\title{
ABSTRACTS IN ECHOCARDIOGRAPHY
}

RELATIONSHIP BETWEEN EXERCISE STRESS ECHO TEST RESULTS AND CORONARY STENOSIS SEVERITY

P Cokkinos, L Rallidis, D Tousoulis, Graham Davies, Petros Nihoyannopoulos. Cardiology Unit, RPMS, Hammersmith Hospital London UK.

Quantitative coronary angiography has been shown to allow the functional assessment of coronary stenosis. The relationship between exercise stress echo (ESE)-induced wall motion abnormalities and stenosis severity however remains controversial. We quantified stenosis severity by computerised angiography in 30 patients (mean age $58 \mathrm{y}, 23$ male) undergoing ESE, with single vessel coronary artery disease ( $250 \%$ minimum luminal reduction) and stable angina. All patients had normal resting left ventricular function and no previous history of myocardial infarction. Exercise test was performed according to modified Bruce protocol. Positive ESE was defined as occurrence of wall motion abnormality. The left ventricle was divided into 11 segments and the walls were scored as: $1=$ normokinetic, 2 =hypokinetic, 3 =akinetic, and $4=$ dyskinetic. 23 patients developed wall motion abnormalities during ESE (group 1) and 7 did not (group 2). In 15 of $23(65 \%)$ patients the positive ESE for wall motion abnormality was associated with ECG changes during exercise. The results of two groups were:

\begin{tabular}{|c|c|c|c|c|c|c|c|}
\hline \multirow{2}{*}{ 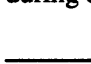 } & \multirow{2}{*}{\multicolumn{3}{|c|}{ Baseline }} & \multicolumn{3}{|c|}{ Peak exercise } & \\
\hline & & & & $\mathbf{B P}$ & $\mathbf{H I R}$ & Score & St $\geq$ \\
\hline
\end{tabular}
group2 $126+3.571+4.8110 \pm 0.0169 \pm 5.0^{*} 143 \pm 10^{*} 11.0 \pm 0.0^{+} 1 / 7(14 \%)^{+}$ $*=p<0.01$ vs baseline, ${ }^{+}=p<0.01$ vs group 1

St=stenosis with $\geq 80 \%$ severity, $B P=$ blood pressure, $\mathrm{HR}=$ heart rate

A significant correlation was found between stenosis severity and wall motion abnormality score during peak exercise $(\mathrm{r}=0.56$, $\mathrm{p}<0.01$ ).

In conclusion, in patients with single vessel disease the wall motion abnormality score during peak exercise significantly correlates with coronary stenosis severity. Positive ESE is usually associated with a stenosis severity $\geq 80 \%$. Moderate stenosis (severity $<80 \%$ ) is more often associated with negative ESE results in single vessel disease. Moreover a positive ESE for wall motion abnormality is not always associated with ECG changes during exercise.

LIMITS OF AGREEMENT BETWEEN APPROACHES TO EVALUATING CARDIAC FUNCTION USING NON-INVASIVE ULTRASOUND IMAGING AND DOPPLER

Mr. D.I. Parsons, Cardio-Respiratory Laboratory, Bolton General

Hospital

This study investigated the use of commonly employed models to assess left ventricular ejection fraction in echocardiography. Similar studies have used correlation coefficients to show agreement. Bland and Altman (1986) showed this approach to be in error and suggested an alternative method of analysis. Limits of agreement for the inter and intra-operator variability, and for the cross technique agreement were derived. Fifty echocardiographic investigations, requested for ejection fraction measurement, were duplicated by the same single operator, with the patients consent, to assess repeatability. Additionally, a second operator measured the ejection fraction on nine of these patients. The measurement methods compared were; Teichholz, Bullet, Area-length, Modified Simpsons, and subjective evaluation. The reproducibility of the Modified Simpson's approach to evaluating left ventricular function using a single operator was within $10 \%$ According to the techniques suggested by Bland and Altman (1986), the coefficient of repeatability at 0.95 confidence are from $-9.77 \%$ to $+9.55 \%$. This encompasses the range of values possible from simple operator error, or variability. In practical terms, this means that, if we were investigating the improvement in cardiac function after introduction of an ACE inhibitor, the improvement would have to be more than $9.55 \%$ improvement if we are to be confident of a real improvement in cardiac function. The other techniques fared less well, in order of reproducibility (coefficient of repeatability in brackets) were: subjective scoring (12.37\%), Teichholz (12.82), Bullet (12.92), Area/Length method (16.15). These results would imply that marked variation in results from one occasion to another can occur in the absence of any pharmacological or physiological change, and these techniques are unsuited to serial use. Interoperator repeatability for Modified Simpson's was less promising at $21.95 \%$. The best inter-operator result was obtained from subjective scoring at $14.14 \%$, followed by Teichholz (20.03), Modified Simpson's, Bullet (25.57), Area/Length (27.37). Comparison of results obtained in the study sample, using the respective models, showed no cross technique agreement. There were no clinically useful relationships between the results of any of the techniques. It is necessary to think carefully about the measurement choice when approaching a potential serial study scenario. Wherever possible the same operator should measure the ejection fraction, using the identical approach, to optimise the chance of reproducibility, and ensure that any perceived change (given the repeatability coefficient for the chosen approach) is real
Does Long or Short Axis Contraction of Left Ventricle Measured by Doppler Myocardial Imaging Correlate with Global Left Ventricular Systolic Function?

Azhar A Khokhar, Dragos I Vinereanu, Ann C Tweddel, Alan G Fraser. University of Wales College of Medicine, Cardiff, United Kingdom.

To determine if measurement by Doppler Myocardial Imaging (DMI) of left ventricular (LV) long and short axis contraction can estimate global LV systolic function we prospectively examined 39 subjects ( $57 \pm 10$ years). 23 patients had prior myocardial infarction, 10 had ischaemic heart disease with no infarction while 6 were normal. Long axis contraction of LV was assessed by measuring the peak systolic velocities (V) and time velocity integrals (TVI) of the medial and lateral mitral annulus by pulsed wave DMI in apical 4 chamber view. Three consecutive complexes were averaged. Short axis contraction was similarly assessed at the posterior basal LV wall. LV ejection fraction was measured by radionuclide ventriculography (list mode, for 10 million counts, 32 frames/cycle). Both medial and lateral mitral annular TVI showed modest correlations with ejection fraction. Mitral annular velocities showed weak correlations (table)

\begin{tabular}{|l|c|c|}
\hline & $\mathbf{r}$ & $\mathbf{p}$ \\
\hline Lateral V & 0.34 & 0.032 \\
\hline Lateral TVI & 0.55 & $<0.001$ \\
\hline Medial V & 0.36 & 0.023 \\
\hline Medial TVI & 0.51 & $<0.001$ \\
\hline
\end{tabular}

Short axis DMI of LV posterior wall (V\&TVI) did not correlate with ejection fraction

Conclusion: In patients with ischaemic heart disease DMI of mitral annular longitudinal motion is an imprecise indicator of global LV systolic function.

\section{LEFT VENTRICULAR LONG AXIS FUNCTION IMPROVES THE ACCURACY OF DOBUTAMINE STRESS} ECHOCARDIOGRAPHY

MB Mishra, R Cooke, DA Lythall, JB Chambers. Department of Cardiology, Guy's and St Thomas' NHS Trust, London

Left ventricular long axis contraction is a sensitive indicator of ventricular dysfunction and may be helpful in the diagnosis of ischaemia during stress echocardiography. Methods: We investigated long axis function during dobutamine stress echocardiography (5 to $40 \mu \mathrm{g} / \mathrm{kg} / \mathrm{min}, 3$ minute stages) in 70 consecutive subjects (mean age 53 yrs, $13 \mathrm{~F}, 57 \mathrm{M}$ ) who also had coronary angiography (17 with normal coronary arteries, group A, 53 with significant disease, defined as $>70 \%$ stenosis, group B). The amplitude (LAS) and peak velocity (PVS) of long axis shortening were averaged over three beats at each stage using the $\mathrm{M}$ mode cursor placed at the medial and lateral mitral annulus in the apical four chamber view (averaged for both sites). Isovolumic contraction time (IVCT) was measured from the $Q$ wave to start of long axis contraction. Results: At rest LAS was lower in group B $(1.17(0.25) \mathrm{cm}$ vs. $1.29(0.29) \mathrm{cm}$ in group $\mathrm{A}, \mathrm{p}=0.07)$ and remained so to peak $(1.19(0.31) \mathrm{cm}$ vs $1.66(0.23) \mathrm{cm}, \mathrm{P}<0.001)$. In group B PVS was also lower at rest $(4.6(1.4) \mathrm{cm} / \mathrm{s}$ vs. $6.2(2.1) \mathrm{cm} / \mathrm{s}$ group $A, P<0.001)$ and did not increase as much as in the normals (group B $7.4(2.9) \mathrm{cm} / \mathrm{s}$ group A $10.8(2.9) \mathrm{cm} / \mathrm{s}$ at peak, $\mathrm{p}=0.04$ ). IVCT was consistently longer in group B (rest 83 (17) msec vs 58 (9) msec in group $A, P=0.01$, peak $52(18) \mathrm{msec}$ vs $31(9) \mathrm{msec}$ in group A, $P=0.03$ ). Change in LAS $<0.25 \mathrm{~cm}$ from rest to peak was the best discriminator for coronary artery disease and was used for furthe analysis. Wall motion analysis (excluding resting abnormality) had a sensitivity of $58 \%$ for the prediction of coronary artery disease and a specificity of $94 \%$. This was improved with the addition of long axis function to a sensitivity of $85 \%$, specificity $89 \%$. Conclusions: a) Long axis function improves the sensitivity and specificity of dobutamine stress echocardiography and b) provides a quantitative measure of ventricular dysfunction during stress echocardiography. 
ENHANCED ECHOCARDIOGRAPHIC DETECTION OF MYOCARDIAL ISCHAEMIA WITH INOTROPIC STRESS COMPARED TO ERGOMETRIC EXERCISE.

R S Khattar, A Lahiri, R Senior. Northwick Park Hospital, Harrow.

The extent of inducible ischaemia detected by stress echocardiography (Echo) is a good marker of prognosis in patients (pts) with coronary artery disease (CAD). Supine bicycle exercise (Ex) and inotropic stress echocardiography are increasingly used for this purpose. Arbutamine (Arb) is a new synthetic catecholamine developed specifically for stress testing using a closed loop delivery device. To compare the relative value of Ex and Arb Echo for detecting the presence, extent and severity of $\mathrm{CAD}$ and inducible ischaemia, 26 pts undergoing coronary arteriography underwent both techniques in random order. Images were analysed blindly using a 12 segment left ventricular model. Each segment was graded from 1 to $4(1=$ normal, $4=$ akinetic $)$ for both stress techniques. Total systolic wall thickening scores (WTS) were calculated at peak stress indicating the extent and severity of CAD, and the difference in scores between rest and stress ( $\triangle W T S$ ) gave an index of inducible ischaemia for each stress modality. Angiographic evidence of $a \geq 50 \%$ stenosis in at least one of the major coronary arteries was considered significant. 12 pts had multivessel disease, 6 had single vessel disease and 8 had normal coronary arteries. The peak rate pressure product was significantly higher for Ex compared to Arb stress $\left(22.2 \times 10^{3}\right.$ vs $\left.17.5 \times 10^{3} ; \mathrm{p}=0.002\right)$. However, the diagnostic accuracies for the detection of $\mathrm{CAD}$, were similar for the two techniques (Arb Echo 92\%, Ex Echo $85 \%$ ). Mean \pm s.d. WTS at peak stress was $21.3 \pm 8$ for Arb Echo and 15.5 \pm 4.3 for Ex Echo $(p<0.001)$. Similarly, $\Delta$ WTS was significantly greater for Arb Echo compared to Ex Echo $(8.1 \pm 7.3$ vs $2.6 \pm 4.1$, respectively; $\mathrm{p}<0.001)$. Therefore, Arb Echo is superior to Ex Echo for detecting the extent and severity of both $\mathrm{CAD}$ and inducible ischaemia and this may have important prognostic implications.

\section{SUPERIORITY OF ARBUTAMINE OVER DIPYRIDAMOLE} FOR THE STRESS ECHOCARDIOGRAPHIC ASSESSMENT OF CORONARY ARTERY DISEASE AND REVERSIBLE ISCHAEMIA

P Soman, R Khattar, A Lahiri, R Senior. Northwick Park Hospital, Harrow.

Stress echocardiography is an established method of detecting coronary artery disease (CAD) and inducible ischaemia. However, there are conflicting reports on the relative merits of vasodilator and inotropic stress agents for this purpose. We performed arbutamine and on a separate day, high dose $(0.84 \mathrm{mg} / \mathrm{kg})$ dipyridamole echocardiography in 27 patients undergoing coronary arteriography. The left ventricle was divided into 12 segments which were then graded according to wall thickening ( $1=$ normal, $2=$ mildly reduced $3=$ severely reduced, $4=a b s e n t)$. CAD was diagnosed in the presence of a resting or stress induced wall thickening abnormality and inducible ischaemia was indicated by a new or worsening abnormality occurring on the stress study. The extent and severity of CAD and inducible ischaemia was determined by the sum of individual segment scores at peak stress (peak stress score) and the difference between the stress and rest scores ( $\Delta$ score) respectively. Angiographic evidence of $\geq 50 \%$ stenosis was considered significant. Of the 27 patients, 21 had $\mathrm{CAD}$ and 15 had multivessel disease.

$\begin{array}{llll} & \text { Sensitivity } & \text { Specificity } & \text { Single Vessel Disease } \\ \text { Arb Echo } & 100 & 83 & 100 \\ \text { Dip Echo } & 61 & 100 & 50 \\ \text { p Value } & 0.001 & 0.3 & 0.004\end{array}$

$\begin{array}{lll}\text { p Value } \quad 0.001 & 0.3 & 0.004 \\ \text { The extent and severity of disease detected by arburtamine echo was }\end{array}$ significantly greater than dipyridamole echo (mean peak stress scores $24.95 \pm 6.54$ and $14.52 \pm 4.03$ respectively, $p<0.001$ ). Furthermore, arbutamine echo detected more reversible ischaemia than dipyridamole echo (mean $\Delta$ score $11.81 \pm 6.38$ and $1.62 \pm 3.4$ respectively, $p<0.001$ ). Thus, arbutamine echocardiography detects more disease and inducible ischaemia than dipyridamole echocardiography, and thus it may also have superior prognostic value.
DOPPLER MEASUREMENT OF RIGHT VENTRICULAR PRESSURE WITH EXERCISE IN REPAIRED TETRALOGY

TN Bloomer, JB Ball, GJ Williams

Department of Cardiology, Killingbeck Hospital, Leeds.

Patients with surgically repaired Tetralogy of Fallot have dilation of the right heart which may later lead to arrhythmias and right heart failure. Right ventricular pressure is routinely estimated from the peak of the tricuspid regurgitant (TR) Doppler signal using the modified Bernouilli equation during resting echocardiography. In the absence of significant right ventricular outflow tract obstruction this is also used as a measure of pulmonary artery pressure. Continuous wave Doppler echocardiography of the tricuspid regurgitant signal was undertaken in nine patients with repaired Tetralogy of Fallot at rest and during increasing supine bicycle exercise. Each patient generated an increase in heart rate (HR) and the estimated right ventricular systolic pressure during exercise (see table).

\begin{tabular}{|c|c|c|c|}
\hline $\begin{array}{c}\text { Patient } \\
\text { identifier }\end{array}$ & $\begin{array}{c}\text { TR change } \\
\text { (mmHg) }\end{array}$ & $\begin{array}{c}\text { HR change } \\
\text { (bpm) }\end{array}$ & $\begin{array}{c}\text { Exercise } \\
\text { level (Watts) }\end{array}$ \\
\hline 1 & 32 & 72 & 125 \\
\hline 2 & 24 & 43 & 125 \\
\hline 3 & 29 & 45 & 100 \\
\hline 4 & 23 & 77 & 100 \\
\hline 5 & 14 & 36 & 75 \\
\hline 6 & 17 & 23 & 75 \\
\hline 7 & 19 & 23 & 50 \\
\hline 8 & 7 & 22 & 50 \\
\hline 9 & 4 & 16 & 40 \\
\hline
\end{tabular}

The increase in the tricuspid regurgitant pressure from rest to peak exercise shows a linear relationship to the maximum work rate achieved $(r=0.86, p<0.05)$. There was no correlation between resting TR and maximum work achieved. Estimation of the right ventricular systolic pressure during exercise may provide additional information about right ventricular systolic function

\section{ECHOCARDIOGRAPHIC ASSESSMENT OF AORTIC ROOT IN} CHILDREN WITH BICUSPID AORTIC VALVE

K R Trivedi, W S James, D G Wilson, V J Booker, A G Stuart. Congenital Heart Disease Centre, University Hospital of Wales Healthcare NHS Trust, Cardiff.

There is substantial evidence to suggest that there may be a common developmental defect which can cause bicuspid aortic valve, coarctation of aorta and a fragile aortic media. Therefore, in individuals with bicuspid aortic valve there is a potential risk of aortic root dilatation, dissection and rupture. We have identified patients with bicuspid aortic valve referred as children to the Congenital Heart Disease Centre in order to determine haemodynamic status of valve, prevalence of aortic root

dilatation/dissection and associated coarctation, and frequency of progression to aortic root surgery. Data were obtained via the unit database (Cardiobase) for the period June 1991-August 1995. Echocardiograms with full doppler and cross-sectional imaging, performed using an Acuson 128 $\mathrm{XP} / 10 \mathrm{C}$, were analysed to : $1 /$ confirm aortic valve morphology, $2 /$ measure aortic root dimensions with reference to body surface area using the technique of Roman(1), 3/ assess the degree of valve stenosis, regurgitation and presence of coarctation. 45 patients with bicuspid aortic valve were identified. Age ranged from 1 month to 32 years (median 10 years 2 months). $30(67 \%)$ were males. $20(44 \%)$ had doppler evidence of aortic stenosis: 16 mild (Vmax: 1.5-2.9 m/s); 3 moderate (Vmax: 3.0-4.5 m/s); 1 severe (Vmax : $>4.5 \mathrm{~m} / \mathrm{s}) .11(24 \%)$ had aortic regurgitation : 2 trivial; 8 mild to moderate; 1 severe. $13(29 \%)$ had a dilated aortic root $(>95$ th centile for body surface area) : $5(38 \%)$ of these had valve stenosis and $5(38 \%)$ had regurgitation. $2(15 \%)$ of those with dilated root progressed to surgery requiring aortic root replacement. $24(53 \%)$ had coarctation of whom 7 ( $29 \%$ ) had dilated aortic root. We conclude that aortic root dilatation is common in patients presenting with bicuspid aortic valve as children. The lesion is not always benign and detailed echocardiography with serial measurement of aortic root dimensions allows rational follow up. Reference: (1) Two dimensional echocardiographic aortic root dimensions in normal children and adults, Roman MJ et al., Am. Journal of Cardiology, 1989;5: 507-12. 
USE OF LARYNGEAL MASK AIRWAY ANAESTHESIA FOR TRANSOESOPHAGEAL ECHOCARDIOGRAPHY

SS Adwani, A Cranston, JV DeGiovanni. Department of Cardiology and Department of Anaesthesia, Birmingham Children's Hospital NHS Trust, Birmingham.

Transoesophageal echocardiography (TOE) in paediatric patients and adults with congenital heart disease is usually performed under general anaesthesia (GA) using tracheal intubation. Laryngeal mask airway (LMA) has been introduced in anaesthesia as an alternative to the face mask or tracheal intubation for airway maintenance. We performed a prospective clinical trial in a tertiary referral centre to determine the feasibility of TOE using LMA anaesthesia. TOE was performed in 16 patients during LMA anaesthesia. There were 10 males and 6 females; the age range was 52 months to 69 years (median 11.3 years), weight range $18.9 \mathrm{~kg}$ to $78.5 \mathrm{~kg}$ (median 34.4 $\mathrm{kg}$ ). An appropriate size LMA was inserted in all patients at first attempt. Anaesthesia was induced with propofol and maintained with inhalational mixture of oxygen, nitrous oxide and isoflurane. Patients were allowed to breathe spontaneously during the TOE. Patient monitoring consisted of ECG, noninvasive BP, pulse oximetry and inspired oxygen concentration. The anaesthesia was maintained for an average time of 28 minutes (range 15 mins to 45 mins). TOE was successfully performed in all patients. Hemodynamics remained stable during the procedure. Laryngospasm, cough at induction, postoperative airway or pulmonary complications were not seen in any patients. Fourteen of the 16 patients were discharged on the same day while 2 remained inpatient for subsequent cardiac surgery. LMA provides a safe and secure airway and could replace tracheal intubation for TOE in selected patients who require GA.

IS MY REPORT DEFENSIBLE?: THE EVOLVING PROFESSIONAL ROLE OF THE ECHOCARDIOGRAPHER

J. Varley. Seacroft Hospital, Leeds. England.

Non-medical echocardiographers are being asked to perform and report on echocardiograms in the absence of any supervisory medical support. The aim of this study was to determine the level of experience and training in echocardiography within the Yorkshire Regional Health Authority, and to ascertain the level of knowledge of aspects of cardiac ultrasound reporting, as most technicians do not hold formal qualifications in echocardiography. A structured interview was conducted with staff in all hospitals having an echocardiography department. Eighteen of these were NHS and three were private hospitals. Ninety echocardiographers were interviewed: $72 \%$ were technicians and $28 \%$ were clinicians and of these, $40 \%$ of clinicians and $60 \%$ of technicians were members of BSE. Questions asked in the interview schedule were related to reporting and medico-legal issues. Only $9 \%$ of the technicians had personal indemnity insurance and $37 \%$ of technicians were not aware of their medico-legal status when issuing reports. When asked about the DOH requirements for storage of hard-copy, only $8 \%$ of clinicians and $28 \%$ of technicians thought that they knew the answer. No-one gave the correct answer. BSE and UKAS have issued guidelines for working practice but, there are echocardiographers who do not belong to either of the professional bodies. These remain ill-informed and possibly at greater risk of litigation. The professional role of the echocardiographer is changing within the evolutionary waves of Trusts in the NHS. Other professional groups of medical auxiliaries have raised their academic standards and, in doing so, have raised their profile within the multi-disciplinary groups. Many technicians are not in a position to adequately write reports and now is the time to ensure that adequate training and education is developed. The medico-legal aspects of non-medically qualified echocardiographers performing and reporting scans are discussed, and their future professional role is critically analysed.
OPEN ACCESS ECHOCARDIOGRAPHY : A SURVEY OF ITS PROVISION IN THE UK TODAY

HM Rimington, JB Chambers.

Adult Echocardiography, Guy's Hospital, London.

Open access echocardiography is a fashionable new concept but little is known about how it is developing in the UK today. We therefore conducted a telephone survey of the echocardiography departments at 100 U.K. hospitals in the first quarter of 1996. The hospitals were selected from the General Medical Directory if they had at least one General Medical Consultant and were described as "acute" with more than 300 beds. Teaching Hospitals and District General Hospitals from all regions of the UK were included. The definition of open access was that the General Practitioner (GP) could directly contact the echocardiography department to arrange the test and that no screening of requests occurred. All hospitals had echo services and 30 were offering open access echocardiography. Of these, $21(70 \%)$ had been providing the service for one year or less. A further 11 hospitals were planning to start an open access service in the near future. The schemes differed considerably. $15(50 \%)$ were completely open to all GPs, the remainder imposed restrictions ( eg. Fund Holders only). In 26 (87\%) the echoes were performed by a technician/radiographer, and in 13 $(42 \%)$ studies were not reviewed or reported by a physician. Between 25 and 1300 open access echoes were performed per year representing $0.5-29 \%$ of the total workload. Only $16(53 \%)$ hospitals provided educational material or a lecture prior to the implementation of the scheme. $32 \%$ of the schemes were funded by pharmaceutical companies and $10 \%$ by research grants.

It can be concluded that:

(1) Open access echocardiography is rapidly becoming more widely available to GPs.

(2) The type of service offered differs widely between hospitals.

We suggest that formal guidelines for open access echocardiography should be debated.

TRANSOESOPHAGEAL ECHOCARDIOGRAPHY IS NOT INDICATED IN PATIENTS AT LOW RISK OF ENDOCARDITIS M.L. Witherspoon, J.D. Gillmore, E.Wu, S.Takeda, J.B. Chambers Adult Echocardiography, Guys Hospital, London, U.K.

The benefits from transoesophageal echocardiography may depend on the clinical likelihood of infective endocarditis, but little data exist on patients at low risk. We therefore assessed the benefit of transoesophageal (TOE) over transthoracic echocardiography (TTE) in 25 patients with renal failure with either low (15/25) or high (10/25) levels of clinical suspicion for infective endocarditis (IE). Diagnostic benefit was defined by as: 1) mass consistent with vegetation shown only on TOE, 2) diagnostic certainty gained by TOE, 3) complications found only by TOE. Low suspicion ( $\mathrm{n}=15)$ constituted pyrexia, murmur, and blood cultures which were negative or grew organisms unlikely to cause IE. High suspicion $(n=10)$ was defined as pyrexia , murmur, and blood cultures growing organisms likely to cause IE (all Streptococci or Staphylococci). Studies were performed using a Hewlett Packard Sonos 2500 with 2.5 and $3.5 \mathrm{MHz}$ probes and a 5.0 $\mathrm{MHz}$ omniplane TOE probe. In low risk cases TOE gave no new information whether TTE was normal $(n=7)$ or abnormal $(n=8)$ although it confirmed that echogenic masses were more likely to be calcific deposits than vegetations. In high risk cases TTE was always abnormal but TOE added new information in $7 / 10$ cases, positively in 6 and by exclusion in one. TOE detected signs of complications in one case. We conclude that when clinical suspicion for endocarditis is low, transoesophageal echocardiography is rarely necessary. 
IVUS OUANTIFICATION OF HEART TRANSPLANT

\section{VASCULOPATHY}

MA Appleby, A Coumbe*, M Yacoub, NR Banner.

Department of Cardiology and Transplant Medicine, Harefield Hospital. *Royal Hospitals NHS trust, London.

Background : Transplant vasculopathy is the leading cause of long term morbidity and mortality in heart transplant patients. Conventional angiographic assessments only give a silhouette view of the vessel with no information about ptaque thickness. We discuss validation of an Intravascular Ultrasound (IVUS) based technique for quantification of plaque burden.

Methods: 10 pressure fixed post-mortem hearts were imaged using IVUS and histologically sectioned. Longitudinal positioning of the IVUS catheter was achieved using an electronic pullback device. IVUS images and histological sections were digitised on an Apple Mac ${ }^{\circ}$ Power $\mathrm{PC}^{\oplus}$. Plaque burden was quantified using image processing software (Thresholding and Bezier curve algorithm) and image analysis software (NIH Image \%). 3D reconstructions of the IVUS and histology was undertaken using Spyglass software. Construction of an ECG gated microprocessor withdrawal device enabled application of the technique to assessment of plaque burden in transplant patients.

\begin{tabular}{|l|c|c|}
\hline Results: & $\begin{array}{c}\text { Histology volume } \\
\text { (mm3) }\end{array}$ & $\begin{array}{c}\text { IVUS volume } \\
\text { (mm3) }\end{array}$ \\
\hline Inner luminal area (ILA) & $333 \pm 31$ & $287 \pm 28$ \\
\hline Media bounded area (MBA) & $471 \pm 48$ & $431 \pm 92.4$ \\
\hline Plaque burden (MBA-ILA) & $138 \pm 12$ & $137 \pm 13$ \\
\hline
\end{tabular}

Mean plaque burden volumes were in good agreement between IVUS and histology (Mean ratio 0.99 with $99 \%$ confidence intervals of 0.80 to 1.19 ). Development of a microprocessor controlled ECG-gated withdrawal device has enabled application of the technique to patient studies. 16 baseline IVUS studies have been undertaken at Harefield hospital in patients following heart transplants. Requantification of plaque burden after one year will assess progression of transplant coronary artery disease.

Conclusions: Use of IVUS, a programmable withdrawal device, image processing software and NIH Image enable accurate quantification of plaque burden. Application to heart transplant patients is potentially important in assessing treatments designed to reduce development of transplant coronary artery disease.

\section{ECHOCARDIOGRAPHIC PREDICTORS OF POSTOPERATIVE MYOCARDIAL FAIIUURE IN MITRAL REGURGITATION EM Lee, FC Wells and LM Shapiro. Papworth Hospital, Cambridge.}

Myocardial failure is the single greatest cause of morbidity and mortality after surgery for mitral regurgitation. Mitral regurgitation may mask deteriorating left ventricular function and prognostication remains difficult. We examined the value of echocardiography for risk stratification. Pre-op echocardiograms were available for review in 227 of 494 consecutive patients who underwent surgery for mitral regurgitation. Baseline characteristics and outcome in patients with and without available pro-op echocardiograms were similar. On multivariate analysis with end points of post-op myocardial failure and death of myocardial failure, pre-op NYHA class, age 270 years and some left ventricular [LV] parameters (systolic internal diameter [SD], calculated ejection fraction $[\mathrm{EF}]$, visual estimate of function [VE]) were significant prognostic indicators. Sex, heart rhythm, type of operation, coronary artery disease, aortic valve disease, cause and severity of mitral regurgitation, left atrial size and LV diastolic internal diameter were not. \begin{tabular}{|l|l|lllll|l|}
\hline Grading systems used for multivariate analysis and numbers of patients \\
\hline EF\% & n & EF & Function & n VE1 VE2 & SD(mm) n & SD1 & SD2
\end{tabular}

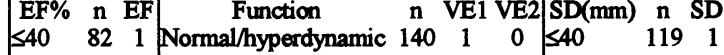
$\begin{array}{lllllllllll}41-50 & 61 & 2 & \text { Mild impairment } & 42 & 2 & 0 & 41-45 & 46 & 2 & 2\end{array}$ \begin{tabular}{lllllll|llll|l}
$51-60$ & 62 & 3 & Moderate impairment & 40 & 3 & 1 & $46-50$ & 32 & 3 & 2
\end{tabular} \begin{tabular}{llllllllllll}
$>60$ & 22 & 4 & Severe impairment & 5 & 4 & 1 & $>50$ & 30 & 4 & 3 \\
\hline
\end{tabular} 4 year freedom from DMF/AMF

\begin{tabular}{|c|c|c|c|c|}
\hline Grade & EF & VE1 & SD1 & SD2+VE2 \\
\hline 1 & $85 \pm 6 / 76 \pm 6$ & $93 \pm 3 / 81 \pm 4$ & $90 \pm 4 / 81 \pm 5$ & $94 \pm 3 / 82 \pm 4$ \\
\hline 2 & $91 \pm 4 / 79 \pm 6$ & $88 \pm 6 / 66 \pm 8$ & $90 \pm 5 / 62 \pm 9$ & $86 \pm 5 / 74 \pm 6$ \\
\hline 3 & $88 \pm 5 / 66 \pm 7$ & $77 \pm 8 / 57 \pm 9$ & $93 \pm 5 / 77 \pm 8$ & $85 \pm 7 / 58 \pm 10$ \\
\hline & $78 \pm 10 / 58 \pm 12$ & $75 \pm 22 / 38 \pm 29$ & $71 \pm 10 / 43 \pm 13$ & $70 \pm 14 / 25 \pm 10$ \\
\hline \multicolumn{5}{|c|}{ Multivariate analysis of age, NYHA class and LV parameters, $P / \operatorname{Exp}(\mathrm{B})$} \\
\hline \multirow{3}{*}{$\begin{array}{l}\text { DMF } \\
\text { AMF }\end{array}$} & EF & VE1 & SD1 & SD2+VE2 \\
\hline & $0.2240 / 1.26$ & $0.0104 / 1.70$ & $0.0020 / 2.30$ & $0.0013 / 1.88$ \\
\hline & $0.0033 / 1.45$ & $0.0011 / 1.55$ & $0.0005 / 1.83$ & $0.0001 / 1.64$ \\
\hline
\end{tabular}
Simple echocardiographic assessment of left ventricular function provides effective clinical risk stratification. Although LVEF is the measure most commonly used in clinical practice, visual estimates by experienced echocardiographers and LVIDS are more accurate predictors of outcome and should be preferred.
THE RELATIONSHIP BETWEEN PRESSURE DROP AND FLOW DURING DOBUTAMINE INFUSION IN PATIENTS WITH AORTIC STENOSIS

S Takeda, H Rimington, JB Chambers.

Adult Echocardiography, Guy's Hospital, London

Aortic valve resistance has been suggested as a measure of the severity of aortic stenosis (AS). This concept relies on a direct relationship between pressure difference and flow and this has never been tested in vivo. We therefore studied 13 patients $(6$ male, age 28 to $85 \mathrm{yrs}), 11$ with asymptomatic moderate AS with valve area (AVA) by the continuity equation $0.9-1.0 \mathrm{~cm}^{2}$, and 2 patients with symptomatic severe AS $0.56-0.75 \mathrm{~cm}^{2}$. Studies were performed with a Hewlett-Packard Sonos 2500 using a $2.5 \mathrm{MHz}$ duplex probe and a $1.9 \mathrm{MHz}$ Pedoff continuous wave probe. Dobutamine was infused from $5 \mu \mathrm{g} / \mathrm{kg} / \mathrm{min}$ to $40 \mu \mathrm{g} / \mathrm{kg} / \mathrm{min}$ in three minute stages. Mean transaortic pressure difference (mean $\Delta \mathrm{P}$ ) was calculated from planimetered subaortic and aortic Doppler waveforms using the long form of the modified Bernoulli equation. Flow was calculated from the stroke volume ( $\mathrm{SV}$ in $\mathrm{mls}$ ) and ejection time (EJT in $\mathrm{ms}$ ). Resistance (dynes.s.cm-5) was calculated as $1.333 \times$ mean $\Delta \mathrm{P} \times$ $\mathrm{EJT} / \mathrm{SV}$. In moderate AS there was a linear correlation between $\Delta \mathrm{P}$ and flow $\left(\mathrm{Y}=0.136+0.0985^{*} \mathrm{X}, \mathrm{r}=0.7\right.$, SEE 8.77, $\left.\mathrm{p}=<0.0001\right)$; in severe AS there was a steeper linear relationship ( $Y=-0.632+$ $0.2344^{*} X, r=0.73$, SEE 8.52, $p=0.015$ ). We conclude that the basic assumption of a direct relationship between mean pressure drop and flow is proved thus validating the use of resistance in vivo. Further the slope of the relationship during dobutamine stress may be an additional measure of severity in aortic stenosis.

\section{RIGHT ATRIAL PACING: WHAT EFFECT ON} VENTRICULAR DIASTOLE ?

MRD Belham, H Rimington, C Bucknall, P Holt, J Chambers: Maidstone Hospital, Kent; Guy's and St.Thomas's NHS Trust, London.

Right atrial pacing alters the atrial activation sequence, but it is not known how this affects left or right ventricular diastolic function. We therefore assessed 25 patients with permanent pacemakers; 18 male, aged 34-91yrs. (mean 66yrs.). 15 had echocardiographically normal hearts, 5 had left ventricular hypertrophy, 3 slow filling diastolic patterns and 2 had EF $<40 \%$. All patients were studied in sinus rhythm (SR) then with right atrial pacing (RAP) at sinus rate $+10 \mathrm{bpm}$. We used an Acuson XP10 (with a $2.5 \mathrm{MHz}$ duplex probe), placing the sample volume at the level of the leaflet tips, to record transmitral and transtricuspid flow patterns; the following were averaged over 5 beats:

\begin{tabular}{|lrcrc} 
& SR & RAP & SR & RAP \\
E/A ratio & 0.95 & 0.93 & 1.02 & 1.04 \\
E Deceleration time (ms) & 241 & $262^{\wedge}$ & 251 & 245 \\
Diastolic velocity integral (m) & $\mathbf{0 . 2 1 8}$ & $0.204^{\wedge}$ & 0.185 & $0.165^{\wedge}$ \\
Atrial filling fraction & 0.354 & 0.337 & 0.324 & $0.301^{\wedge}$ \\
Diastolic filling time & 574 & 538 & 636 & 577 \\
Time to atrial systole & 91 & $136^{*}$ & 65 & $91^{*}$ \\
Duration of atrial systole & 191 & 190 & 204 & $183^{*}$ \\
& ${ }^{*} \mathbf{p}<\mathbf{0 . 0 1}$ & ${ }^{\wedge} \mathbf{p}<\mathbf{0 . 0 5}$ & &
\end{tabular}

Despite a similar mean PR interval (SR 168ms and RAP 183ms) the duration of right atrial systole was shorter in RAP and the time to atrial systole was disproportionately lengthened, more for the left than the right heart. The atrial filling fraction was also reduced. We conclude that right atrial pacing is a previously unrecognised factor that affects ventricular filling independently of AV delay. 